\title{
Application and validation of a line-source dispersion model to estimate small scale traffic-related particulate matter concentrations across the conterminous US
}

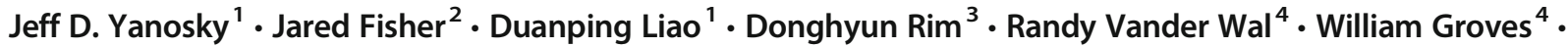 \\ Robin C. Puett ${ }^{5}$
}

Received: 13 December 2017 / Accepted: 23 April 2018 / Published online: 1 June 2018

(C) The Author(s) 2018

\begin{abstract}
Numerous studies document increased health risks from exposure to traffic and traffic-related particulate matter (PM). However, many studies use simple exposure metrics to represent traffic-related PM, and/or are limited to small geographic areas over relatively short (e.g., 1 year) time periods. We developed a modeling approach for the conterminous US from 1999 to 2011 that applies a line-source Gaussian plume dispersion model using several spatially and/or temporally varying inputs (including daily meteorology) to produce high spatial resolution estimates of primary near-road traffic-related PM levels. We compared two methods of spatially averaging traffic counts: spatial smoothing generalized additive models and kernel density. Also, we evaluated and validated the output from the line-source dispersion modeling approach in a spatio-temporal model of 24-h average $\mathrm{PM}<2.5 \mu \mathrm{m}\left(\mathrm{PM}_{2.5}\right)$ elemental carbon (EC) levels. We found that spatial smoothing of traffic count point data performed better than a kernel density approach. Predictive accuracy of the spatio-temporal model of $\mathrm{PM}_{2.5}$ EC levels was moderate for 24-h averages (cross-validation $\left.(\mathrm{CV}) R^{2}=0.532\right)$ and higher for longer averaging times $\left(\mathrm{CV} R^{2}=0.707\right.$ and 0.795 for monthly and annual averages, respectively). $\mathrm{PM}_{2.5}$ EC levels increased monotonically with line-source dispersion model output. Predictive accuracy was higher when the spatio-temporal model of $\mathrm{PM}_{2.5} \mathrm{EC}$ included line-source dispersion model output compared to distance to road terms. Our approach provides estimates of primary traffic-related PM levels with high spatial resolution across the conterminous US from 1999 to 2011. Spatio-temporal model predictions describe 24-h average $\mathrm{PM}_{2.5}$ EC levels at unmeasured locations well, especially over longer averaging times.
\end{abstract}

Keywords Air pollution $\cdot$ Spatial smoothing $\cdot$ Highway proximity $\cdot$ Traffic counts $\cdot$ Dispersion models

Electronic supplementary material The online version of this article (https://doi.org/10.1007/s11869-018-0580-6) contains supplementary material, which is available to authorized users.

Jeff D. Yanosky

jyanosky@phs.psu.edu

Jared Fisher

jafisher@umd.edu

Duanping Liao

dliao@phs.psu.edu

Donghyun Rim

drim@engr.psu.edu

Randy Vander Wal

ruv12@psu.edu

William Groves

wag10@psu.edu
Robin C. Puett

rpuett@umd.edu

1 Department of Public Health Sciences, The Pennsylvania State University College of Medicine, Hershey, PA, USA

2 Department of Epidemiology and Biostatistics, University of Maryland School of Public Health, College Park, MD, USA

3 Department of Architectural Engineering, The Pennsylvania State University College of Engineering, State College, PA, USA

4 John and Willie Leone Family Department of Energy and Mineral Engineering \& The EMS Energy Institute, The Pennsylvania State University College of Earth and Mineral Sciences, State College, PA, USA

5 Maryland Institute of Applied Environmental Health, University of Maryland School of Public Health, College Park, MD, USA 


\section{Background}

Recent epidemiologic studies have documented increased health risks from exposure to atmospheric particulate matter (PM) (Anderson et al. 2012; Beelen et al. 2014; Pelucchi et al. 2009; Shah et al. 2013; Hart et al. 2015; Heinrich et al. 2013; Weuve et al. 2012; Stieb et al. 2012; Rich et al. 2018; Golan et al. 2018) for a variety of health outcomes, including nonaccidental mortality, cardiovascular disease mortality, lung cancer, neurocognitive functioning, and effects on reproduction. Studies using proxy measures for exposure to trafficrelated air pollution have generally reported health effects larger than those for the mass concentration of $\mathrm{PM}<2.5 \mu \mathrm{m}$ $\left(\mathrm{PM}_{2.5}\right)$ or $\mathrm{PM}<10 \mu \mathrm{m}\left(\mathrm{PM}_{10}\right)$ in aerodynamic diameter (Brugge et al. 2013; Gehring et al. 2006; Hoffmann et al. 2007; Puett et al. 2011; Puett et al. 2014; Schikowski et al. 2005). Several of these studies used simple exposure metrics for traffic-related air pollution based on distance to nearest road, or summaries of road geography within buffers of fixed radii (Eckel et al. 2011; Medina-Ramon et al. 2008). More complex approaches have been applied within small geographic areas, typically to one urban area or municipality (Gryparis et al. 2007; Maynard et al. 2007). One such approach accounted for wind direction using a geographic information system (GIS) to calculate the traffic density in locations upwind of receptors (Arain et al. 2007). Trafficrelated air pollutant levels can vary on small (i.e., micro (0$100 \mathrm{~m})$, middle $(100-500 \mathrm{~m})$, and neighborhood (500$4 \mathrm{~km}$ )) spatial scales immediately near roadways (Jerrett et al. 2005; Zhou and Levy 2007). Though the above complex approaches likely described local gradients in trafficrelated air pollutants better than simpler methods such as distance to road terms, few direct, robust, and long-term multi-city comparisons are available. Uncertainty remains about whether and to what extent noise may be a confounder in analyses of health effects of traffic-related PM exposure, which underscores the need for accurate and highly spatially resolved estimation of traffic-related PM levels so these effects can be better disentangled in future epidemiologic analyses.

Gaussian plume dispersion models have been widely used to model point sources (Jerrett et al. 2005) and have been adapted to area and line sources (Benson 1992). Wilton et al. (2010) used such a model, CALRoads-View, to describe small scale gradients in nitrogen oxide $\left(\mathrm{NO}_{\mathrm{x}}\right)$ and nitrogen dioxide $\left(\mathrm{NO}_{2}\right)$ levels for a 2-week period in 2006 in greater Los Angeles and for a 2-week period in 2005 in Seattle. They found that including the output from CALRoads-View improved the prediction capability of city-specific spatio-temporal models of $\mathrm{NOx}$ and $\mathrm{NO}_{2}$ levels compared to traditional land-use regression models.

The objective of the present study was to describe the development of and evaluate the performance of a line-source
Gaussian plume dispersion modeling approach that estimates daily 24-h average traffic-related PM concentrations near roadways which can be applied at any location in the conterminous US from 1999 to 2011. Also, we developed and validated a spatio-temporal model of $\mathrm{PM}_{2.5}$ elemental carbon (EC) using 24-h average measurements of this component of $\mathrm{PM}_{2.5}, \mathrm{PM}_{2.5} \mathrm{EC}$, together with several meteorological and GIS-based spatial covariates (including traffic-related PM levels from our line-source dispersion modeling approach). These models will be used to provide estimates of exposure in epidemiologic analyses. We chose to present results for $\mathrm{PM}_{2.5}$ EC because it has both traffic-related local sources and larger-scale regional gradients (Brochu et al. 2011) and also had high predictive accuracy (spatial cross-validation (CV) $R^{2}=0.784$ (described later)); PM components $\mathrm{Zn}$ and $\mathrm{Cu}$ were also evaluated but had lower predictive accuracy (spatial CV $R^{2}=0.691$ and 0.501 , respectively). We chose not to use $\mathrm{NO}_{2} / \mathrm{NOx}$ as our exposure metric due to our interest in PM health effects and also to the complexity of $\mathrm{NO}-\mathrm{NO}_{2}-\mathrm{O}_{3}$ chemistry in areas very near roadways, though we may address this in future work. Our spatio-temporal model predicts 24-h average $\mathrm{PM}_{2.5}$ EC levels across the conterminous US with high spatial resolution from 1999 to 2011, and thus can provide acute (24-h), sub-acute, or chronic exposure estimates that account for traffic intensity, prevailing wind direction, and dispersion characteristics based on local meteorology.

\section{Methods}

To approximate micro-, middle-, and neighborhood-scale primary traffic-related PM levels, we applied a line-source Gaussian plume dispersion model, Atmospheric Dispersion Modeling System (ADMS)-Roads v2.3 software (CERC, Cambridge, UK), to a hypothetical grid (hereafter referred to as a kernel) with a 2-m cell size under varying meteorological regimes. We calculated traffic-related PM levels at each grid point in the kernel for each combination of ADMS-Roads inputs, and then mapped receptor locations onto the appropriate kernel, with rotation for wind direction if appropriate, to estimate traffic-related PM levels. We chose ADMS-Roads as opposed to other line-source models such as CALRoads-View because of ADMS-Roads' more advanced treatment of atmospheric stability as characterized by continuous MoninObhukov length $\left(L_{\mathrm{MO}}\right)$ and planetary boundary layer height (inputs which are directly available from the Modern Era Retrospective-analysis for Research and Applications (MERRA; http://disc.sci.gsfc.nasa.gov/daac-bin/FTPSubset. $\mathrm{pl}$; see below), resulting in a continuous and nonoverlapping metric of atmospheric stability, as opposed to conventional stability classes. Two hypothetical 5-m road segments, facing each other to eliminate vehicle direction effects, were placed at the origin of each kernel. The domain of each 
kernel was $1 \mathrm{~km}$ wide by $2.05 \mathrm{~km}$ long ( $2 \mathrm{~km}$ downwind of source and $0.05 \mathrm{~km}$ upwind). The ADMS-Roads modeling approach requires several spatially and/or temporally varying inputs in order to produce estimates of near-road traffic-related PM concentrations (referred to as ADMS-Roads output): (1) traffic intensity for each of four road classes (A1, A2, A3, and A4/A6), (2) daily prevailing wind direction, and (3) several parameters which affect pollutant dispersion: wind speed, surface roughness, sensible heat flux, planetary boundary layer height, road width, vehicle speed, and absolute value of minimum $L_{\mathrm{MO}}$. An example kernel is shown in Supplemental Material Fig. S1. The derivation and estimation of these spatially varying or spatio-temporally varying input parameters is described in the following sections. Later we discuss the evaluation and validation of ADMS-Roads output using spatiotemporal models of 24-h average $\mathrm{PM}_{2.5}$ elemental carbon (EC) levels.

Availability of data and material Restrictions apply to the availability of the data used and analyzed in this study, some of which were used under license for the current study and so are not publicly available.

\section{Meteorological inputs to ADMS-Roads}

Meteorological data on wind speed and direction (as $u$-and $v$ - vector wind components at $\sim 10 \mathrm{~m}$ above ground), sensible heat flux, and planetary boundary layer height were obtained from the MERRA project. These data are available hourly on a grid across the continental US with an approximately $55-\mathrm{km}$ (depending on latitude) cell size; the native grid is $0.5^{\circ}$ latitude/longitude. Hourly gridded data were assigned local time and date based on the time zone of each grid point's location and then averaged by day (for wind direction, we averaged $u$ - and $v$-vector components separately, then calculated the direction of the resulting vector) from 1999 to 2011. To allow spatial prediction between the $55-\mathrm{km}$ grid points, the daily averages of each parameter were used to create spatial smoothing generalized additive models (GAMs) of the form:

$y_{\mathrm{it}}=\alpha_{\mathrm{t}}+g\left(s_{\mathrm{i}}\right)+\varepsilon_{\mathrm{it}} ; \varepsilon_{\mathrm{it}} \sim \mathcal{N}\left(0, \sigma_{t}^{2}\right)$

where $y_{\text {it }}$ is the value of the meteorological parameter at location $i=1 \ldots I$ on day $t=1 \ldots T, \alpha_{\mathrm{t}}$ is an intercept representing the adjusted mean on a given day, $g\left(s_{\mathrm{i}}\right)$ is a two-dimensional penalized thin-plate smoothing spline, with basis dimension $k=I * 0.9$ chosen to allow much flexibility in the function. To reduce the potential for overfitting, a multiplier of 1.4 (using the gamma argument to gam()), as recommended by Wood (2006), was used. These daily models were fit separately for each of seven geographic regions (with an overlap of $400 \mathrm{~km}$ with adjacent regions) of the conterminous US (Supplemental Material Fig. S3), yielding seven spatial smoothing GAMs per day to be used for space-time prediction of each daily meteorological parameter at any location in the domain of the conterminous US. The distribution of each of these meteorological parameters was divided into several categories, listed in Table 1, with details of this classification provided in the Supplemental Material.

Location-specific surface roughness and absolute value of minimum $L_{\mathrm{MO}}$ values were derived, in accordance with guidance in the ADMS-Roads software, based on categorization of urban land use data from the 2001 US Geological Survey (USGS) National Land Cover Dataset (USGS 2012; Table 1). The original 30-m cell size data were summarized in ArcGIS v.10 (Environmental Systems Research Institute, Redlands, CA) using a moving window with a $1-\mathrm{km}$ radius to calculate the percentage of low, medium, and highintensity developed land use. Categories of these values are shown in Table 1.

Because we found it had no substantive effect on ADMSRoads output in the range applicable over the conterminous US, air temperature was assumed to equal $15^{\circ} \mathrm{C}$ for all ADMS-Roads output.

\section{Traffic intensity inputs to ADMS-Roads}

We obtained data on annual-average daily traffic counts (hereafter referred to as traffic counts) from Geographic Data Technology, Inc. (Lebanon, NH) Dynamap Traffic Counts v4.2. We first spatially joined the traffic count points (those that reported in or after 1990) to the ESRI StreetMap Pro 2007 network of road segments to obtain the US Census Feature Class Code (US Census Bureau 2013) road class (hereafter referred to as road class) of each road segment. Details regarding the processing of these data can be found in the Supplemental Material. From the processed traffic intensity data, we created four spatial smoothing GAMs: one for each road class (A1, A2, A3, and A4/A6; results shown in Supplemental Material Fig. S4 panels A1b, A2b, A3b, and $\mathrm{A} 4 \mathrm{~b}$, respectively). These spatial smoothing GAMs were of the same form as in Eq. 1 and were validated by calculating the squared Pearson correlation between predicted road-classspecific traffic intensities and those measured in an external validation data set from the US Bureau of Transportation Statistics (BTS) 2011 National Transportation Atlas Database Automated Traffic Recorders (ATR; US BTS 2013) and Weigh in Motion (WIM) (US BTS 2013) data sets. Details regarding the development of the spatial smoothing GAMs of traffic intensity and the processing of the external traffic count validation data can be found in the Supplemental Material. For comparison purposes, we also calculated the 


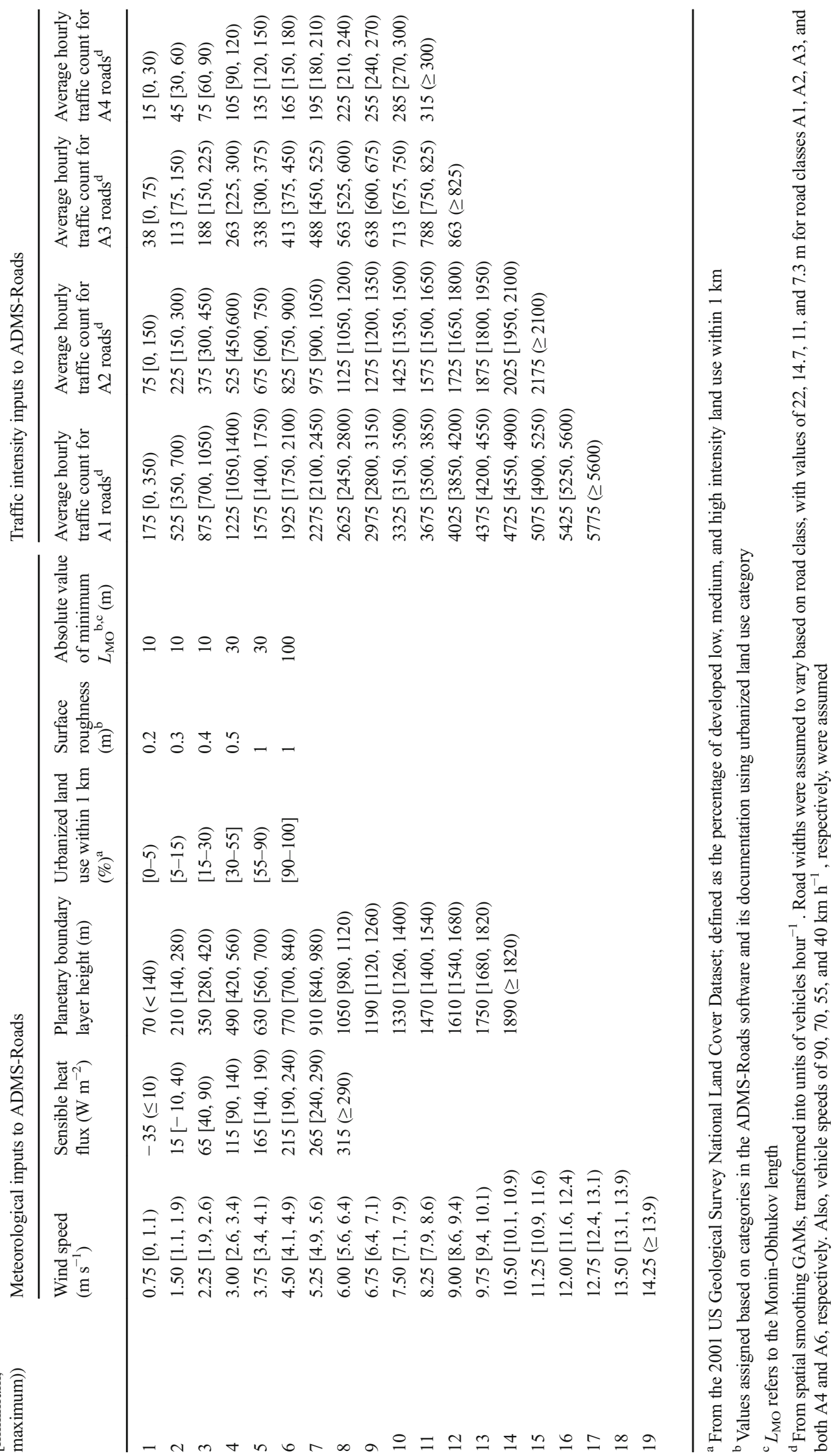


kernel density of the traffic count data using a neighborhood of $100 \mathrm{~km}$ and the ArcGIS "Kernel Density" tool (Silverman 1986). We compared these values to the combined ATR and WIM data by road class using linear regression models.

Because detailed geographic data on road widths and vehicle speeds across the conterminous US were not available, representative road width and vehicle speed values were assumed to be constant based on road class (Table 1).

To provide road source location data, StreetMap Pro 2007 street line segments were converted to a series of points spaced $10 \mathrm{~m}$ apart using the Xtools Pro tool "Convert Features to Points" (Data East, Russia; examples in Fig. 1 and Supplemental Material Fig. S2). The emissions factors we used in ADMS-Roads can be found in the Supplemental Material. We note that our use of a smooth regression spline in the spatio-temporal model of 24-h average $\mathrm{PM}_{2.5}$ EC (hereafter referred to as "spatio-temporal $\mathrm{PM}_{2.5}$ EC model") described below provides an effective scaling of this emission factor to measured $\mathrm{PM}_{2.5} \mathrm{EC}$ levels. Thus, our modeling process eliminates discrepancies between European and US vehicle fleets and between assumed and actual emission rates.

\section{Obtaining ADMS-Roads output}

A separate kernel containing ADMS-Roads output was generated for each combination of meteorological and traffic intensity categories (Table 1; details in Supporting Material). Briefly, to obtain ADMS-Roads output, we first selected the kernel that best matched the dispersion and traffic intensity conditions, then identified road source points within $2 \mathrm{~km}$ of each prediction location. Together with meteorological and traffic intensity inputs predicted from spatial smoothing
GAMs, the ADMS-Roads output concentrations were interpolated from the appropriate kernel, for both "best-estimate" levels which depended on prevailing wind direction and for "worst-case downwind" levels ignoring wind direction. A detailed description of the steps is provided in the Supplemental Material.

\section{Other meteorological and GIS-based spatial covariates}

Data on meteorological parameters air temperature, total precipitation, and total snowfall were obtained from MERRA and processed as described above. Data on daily total rainfall were derived by subtraction of total snowfall flux from total precipitation flux for each day. Though these parameters were not used as inputs to ADMS-Roads, daily spatially smoothed meteorological values were evaluated as spatio-temporal covariates in spatio-temporal models of 24-h average $\mathrm{PM}_{2.5} \mathrm{EC}$. Details on other spatial covariates including county-level population density, elevation (USGS 2013), and distance to road covariates can be found in the Supplemental Material.

\section{Validation of ADMS-Roads output using spatio-temporal models of 24-h average $\mathrm{PM}_{2.5} \mathrm{EC}$}

\section{Statistical models}

Spatio-temporal generalized additive mixed models (GAMMs) of 24-h average $\mathrm{PM}_{2.5}$ EC levels were evaluated and a final prediction model developed with the joint aims of (1) validating and calibrating the ADMS-Roads output to a traffic-related $\mathrm{PM}_{2.5}$ component, and (2) predicting 24-h
Fig. 1 Roadways displayed by US Census feature class code and 10-m street points nearby to a $\mathrm{PM}_{2.5}$ speciation monitor near Linden, New Jersey

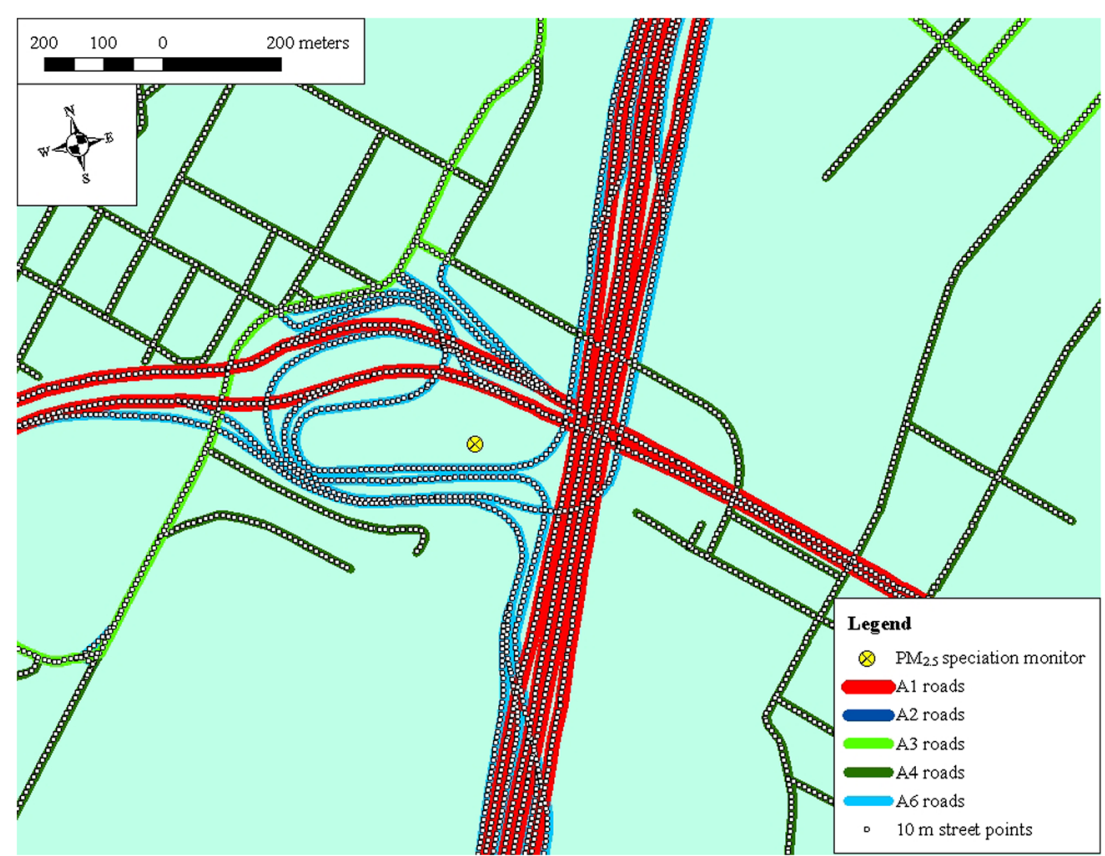


average $\mathrm{PM}_{2.5}$ EC levels at unmeasured locations anywhere in the conterminous US. There were 219,300 24-h site-average $\mathrm{PM}_{2.5}$ EC measurements from 1999 to 2011 at 361 unique monitoring locations. These measurements were available from the Interagency Monitoring of Protected Visual Environments (IMPROVE) network (parameter code 88321; geographic coordinates for two sites were modified, see Supplemental Material for details) and the US Environmental Protection Agency's Chemical Speciation Network (parameter code 88380) on every-third day after August 2001, and alternating every-third and fourth day from January 1, 1999, to that date. $89.7 \%$ of available measurements were from the IMPROVE network. $\mathrm{PM}_{2.5}$ EC measurements were approximately log-normally distributed, and had geometric mean and geometric standard deviation of $154 \mathrm{ng} \mathrm{m}^{-3}$ and 10 , respectively $\left(\mathrm{PM}_{2.5}\right.$ EC measurements ranged from 9.4 to $10,398.8 \mathrm{ng} \mathrm{m}^{-3}$ ). A map showing the locations of the monitors in the conterminous US is shown in Supplemental Fig. S3.

The spatio-temporal GAMM of 24-h average $\mathrm{PM}_{2.5}$ EC levels was similar to that presented in Yanosky et al. (2014), except there monthly averages were used; the model had the following generic form:

$y_{\mathrm{i}, \mathrm{t}}=\alpha+\alpha_{\mathrm{t}}+\sum_{\mathrm{q}} d_{\mathrm{q}}\left(X_{\mathrm{i}, \mathrm{q}}\right)+\sum_{\mathrm{p}} f_{\mathrm{p}}\left(Z_{\mathrm{i}, \mathrm{t}, \mathrm{p}}\right)+g_{\mathrm{t}}\left(s_{\mathrm{i}}\right)+g\left(s_{\mathrm{i}}\right)+b_{\mathrm{i}}+e_{\mathrm{i}, \mathrm{t}} ;$ $b_{\mathrm{i}} \sim N\left(0, \sigma_{\mathrm{b}}^{2}\right) ; e_{\mathrm{i}, \mathrm{t}} \sim N\left(0, \sigma_{\mathrm{et}}^{2}\right)$

where $y_{\mathrm{i}, \mathrm{t}}$ is the natural-log transformed 24-h average $\mathrm{PM}_{2.5}$ $\mathrm{EC}$ (in $\left.\ln \left(\mathrm{ng} \mathrm{m}^{-3}\right)\right)$ for $i=1 \ldots I$ sites $(I=361)$ and $t=1 \ldots T 24-$ $\mathrm{h}$ time periods $(T=1555)$, and $s_{\mathrm{i}}$ is the projected spatial coordinate pair for the $i$ th location. $X_{\mathrm{i}, \mathrm{q}}$ are GIS-based time-invariant spatial covariates for $q=1 \ldots Q, Z_{\mathrm{i}, \mathrm{t}, \mathrm{p}}$ are spatio-temporal covariates for $p=1 \ldots P$, and $\alpha_{\mathrm{t}}$ is a day-specific intercept that represents the adjusted mean across all sites on a given day. $d_{q}$ are one-dimensional penalized spline smooth functions of $Q$ GIS-based time-invariant spatial covariates (basis dimension of seven for each); $f_{p}$ are one-dimensional penalized spline smooth functions of $P$ spatio-temporal meteorological or other covariates (basis dimension of five for each). $g_{\mathrm{t}}\left(s_{\mathrm{i}}\right)$ accounts for residual spatial variability in the 24 -h average values, and $g\left(s_{\mathrm{i}}\right)$ accounts for time-invariant spatial variability across the conterminous US, with both terms specified as spatial bivariate thin-plate penalized splines with basis dimension values: $k_{\mathrm{t}}=I_{\mathrm{t}} * 0.9$ and $k=(I-Q) * 0.9$, respectively. The sitespecific random effect $b_{\mathrm{i}}$ represents unexplained site-specific variability, thus our characterization of the model as a GAMM.

As in previous work, we used a two-stage modeling approach to fit the above model (Eq. 3) (Yanosky et al. 2014). In the first stage (Eq. 4), we estimated site-specific intercepts $\left(u_{\mathrm{i}}\right)$ adjusting for spatio-temporal covariates and residual spatial variability in the 24 -h average values $(N=219,300)$. The spatial terms assumed residual spatial variation was stationarity and isotropic across the domain of the conterminous US.

The first-stage model equation was:

$y_{\mathrm{i}, \mathrm{t}}=u_{\mathrm{i}}+\alpha_{\mathrm{t}}+\sum_{\mathrm{p}} f_{\mathrm{p}}\left(Z_{\mathrm{i}, \mathrm{t}, \mathrm{p}}\right)+g_{\mathrm{t}}\left(s_{\mathrm{i}}\right)+e_{\mathrm{i}, \mathrm{t}} ;$

$e_{\mathrm{i}, \mathrm{t}} \sim N\left(0, \sigma_{\mathrm{e}}^{2}\right)$

and was fit iteratively in a back-fitting arrangement with $u_{\mathrm{i}}+$ $\alpha_{\mathrm{t}}+\sum_{\mathrm{p}} f_{\mathrm{p}}\left(Z_{\mathrm{i}, \mathrm{t}, \mathrm{p}}\right)$ estimated jointly and $g_{\mathrm{t}}\left(s_{\mathrm{i}}\right)$ estimated separately by day (on days where sufficient $\left(>12\right.$ values day ${ }^{-1}$ ) data were available). Variability in the measured concentrations is parsed between the covariates and the residual spatial terms. For the spatial models in the first stage, a multiplier of 1.4 (using the gamma argument to gam()) was used to avoid over-fitting (Wood 2006). All individual fits within the backfitting were preformed using the gam()function in the $\mathrm{mgcv}$ package (Wood 2006) of R (R Development Core Team 2009).

In the second stage, we fit a spatial model to the $\hat{u}_{\mathrm{i}}$ terms obtained from the first-stage model. This model included terms for GIS-based time-invariant spatial covariates and residual time-invariant spatial variability. The second stage (Eq. 5) was:

$$
\begin{aligned}
& \hat{u}_{\mathrm{i}}=\alpha+\sum_{\mathrm{q}} d_{\mathrm{q}}\left(X_{\mathrm{i}, \mathrm{q}}\right)+g\left(s_{\mathrm{i}}\right)+b_{\mathrm{i}} ; \\
& b_{\mathrm{i}} \sim N\left(0, \sigma_{\mathrm{b}}^{2}\right)
\end{aligned}
$$

where $\hat{u}_{\mathrm{i}}$ is an estimated site-specific intercept that represents the adjusted long-term mean at each location $(n=361)$ and the other terms are as above. The second stage was also fit using the gam()function in the mgcv package of $\mathrm{R}$.

\section{Model predictions}

We obtained model predictions by generating the covariates at locations of interest for each, and then transforming to the native scale by exponentiation. To avoid extrapolation, covariates at prediction locations beyond their range among the monitoring locations were set to the appropriate minimum or maximum among the monitoring locations across 1999-2011.

We generated estimates of uncertainty in model predictions (i.e., standard errors) on the natural-log scale using methods described previously (Paciorek et al. 2009; Yanosky et al. 2008). $95 \%$ prediction intervals on the natural-log scale were calculated and exponentiated to assess prediction interval coverage.

\section{Model validation}

10-fold out-of-sample CV was used to evaluate model predictive accuracy and thereby inform covariate selection. Monitoring sites were selected at random and assigned 
exclusively to one of 10 sets. Since the covariate selection process involved fitting multiple candidate models to the same data, set 10 was reserved (i.e., not used for model fitting) to assess whether the covariate selection process contributed to over-fitting (Draper and Krnjacic 2006). Data from sets one to nine were removed from the data set sequentially, with the model fit to the remaining data. Model predictions were then generated and compared to the left-out observations.

The predictive accuracy of the spatio-temporal $\mathrm{PM}_{2.5} \mathrm{EC}$ model levels was determined from the squared Pearson correlation between the left-out observations and model predictions $\left(\mathrm{CV} R^{2}\right)$, with both back-transformed to the native rather than the natural-log scale. Weekly, monthly, and annual averages were calculated after averaging left-out observations and model predictions to the corresponding averaging time. Spatial CV $R^{2}$ values were calculated similarly using the means of the 24-h average values across the entire time period from 1999 to 2011. Prediction errors were calculated by subtracting left-out observations from the model predictions. Bias in model predictions was determined using the normalized mean bias factor (NMBF) (Shaocai Yu, personal communication) and the slope from major-axis linear regression (Legendre 2011) of the left-out observations against the model predictions (both on the natural-log scale). The precision of model predictions was obtained by taking the mean of the absolute value of the prediction errors (CVMAE) and using the normalized mean error factor (NMEF) (Shaocai $\mathrm{Yu}$, personal communication). Formulas for the NMBF and NMEF are provided in the Supplemental Material. Bias and precision values from CV were evaluated overall, and by US Census Division, tertiles of urban land use, season, monitoring network, and monitoring objective. Two thousand seventythree extreme values of $\mathrm{PM}_{2.5}$ EC above the 99th percentile of $1850 \mathrm{ng} \mathrm{m}^{-3}$ were excluded as outliers prior to calculating CV statistics.

\section{Model development and covariate selection}

To determine the best parsimonious prediction model, we fit spatio-temporal models of 24-h average $\mathrm{PM}_{2.5}$ EC levels with alternate versions of ADMS-Roads output (A1, A2, A3 and A4/A6 vs. A1-A3 only; "best-estimate" vs. "worst-case downwind"), with and without various meteorological parameters, and without ADMS-Roads output but instead with GISbased spatial covariates for distance to nearest road by road class. The initial set of meteorological covariates was based on our earlier work (Yanosky et al. 2014). We compared the spatial CV $R^{2}$ among these models, and also among those with and without GIS-based spatial covariates for county-level population density, urban land use, and elevation in the second-stage model. Covariates which were not statistically significant $(p>0.05)$ using the Wald tests (Wood 2006) were removed. We also evaluated whether the direction of the smooth functions met a priori expectations; however, no covariates were removed for this reason.

\section{Results}

\section{Sensitivity of ADMS-roads output to changes in input parameters}

Wind direction, which determines whether the receptor point is downwind of the source, was found to be the most influential ADMS-Roads input parameter. The next most influential input parameters, evaluated at an arbitrary point 100-m downwind of the source, were, in order of decreasing influence: wind speed, surface roughness, sensible heat flux, planetary boundary layer height, absolute value of minimum $L_{\mathrm{MO}}$, and air temperature. These findings were consistent with guidance in the ADMS-Roads User Guide.

\section{Results of smoothing traffic intensity}

The spatial smoothing GAMs of traffic intensity fit the Dynamap traffic count data reasonably well, as evidenced by model $R^{2}$ values of $0.834,0.638,0.533$, and 0.590 for $\mathrm{A} 1-\mathrm{A} 4$ roads, respectively (Table 2 ).

Spatial smoothing GAMs showed generally similar spatial trends across road classes, each showing increased traffic intensity in major urban areas. However, slightly different spatial patterns were evident (Supplemental Material Fig. S4),

Table 2 Results of the external validation of the spatial prediction models of Dynamap traffic counts using ATR and WIM station traffic count data from the US DOT Bureau of Transportation Statistics' National Transportation Atlas Database 2011 ${ }^{\mathrm{A}}$

\begin{tabular}{llll}
\hline Road class $^{\mathrm{b}}$ & $n$ & \multicolumn{2}{l}{ Validation $R^{2 \mathrm{c}}$} \\
\cline { 3 - 4 } & & $\begin{array}{l}\text { Spatial smoothing } \\
\text { GAM }\end{array}$ & $\begin{array}{l}\text { 100-km kernel } \\
\text { density }\end{array}$ \\
\hline A1 & 1712 & 0.524 & 0.316 \\
A2 & 1694 & 0.492 & 0.313 \\
A3 & 1368 & 0.305 & 0.189 \\
\hline
\end{tabular}

"ATR refers to the "Automatic Traffic Recorders" data; WIM refers to the "Weigh-in-Motion" data; DOT is Department of Transportation

${ }^{\mathrm{b}}$ Data for A4 class roads was not available due to the limited number (9) and spatial coverage of stations on these roads

${ }^{\mathrm{c}}$ Obtained from linear regression of predicted traffic counts using Dynamap data and either the spatial smoothing GAM approach or the $100-\mathrm{km}$ kernel density approach versus combined ATR and WIM traffic counts in the external validation data set. Data from ATR or WIM stations with traffic count values beyond the range of the Dynamap traffic count data for each road class were removed because they were likely not spatially matched to the correct road class 
particularly with regard to the extent of influence of major cities in surrounding suburban areas. Additional details regarding spatial trends in traffic intensity and performance of the two spatial averaging methods can be found in the Supplemental Material.

\section{Validation of ADMS-Roads traffic intensity input data}

Validation $R^{2}$ values from linear regression of the combined ATR and WIM traffic counts using the spatial smoothing GAM predictions of the Dynamap traffic count data were $0.524,0.492$, and 0.305 for road classes A1-A3, respectively (Table 2). We also regressed results from the kernel density within 100-km (displayed in Supplemental Material Fig. S4 panels A1c, A2c, A3c, and A4c) approach against the combined ATR and WIM traffic count data; validation $R^{2}$ values were lower as compared to the spatial smoothing GAM approach at $0.316,0.313$, and 0.189 , for road classes A1-A3, respectively (Table 2). In all six regression models discussed above, each of the predicted traffic intensity terms was highly statistically significant $(p<0.001)$ when regressed against the combined ATR and WIM traffic count data for the corresponding road class.

\section{Validation of ADMS-Roads output using spatio-temporal models of 24-h average $\mathrm{PM}_{2.5} \mathrm{EC}$}

\section{Predictive performance of spatio-temporal models of 24-h average $\mathrm{PM}_{2.5} \mathrm{EC}$}

Results from our model comparisons showed that the spatiotemporal model that included ADMS-Roads output summed across only A1-A3 roads exhibited slightly higher predictive accuracy than one that included ADMS-Roads output summed across A1, A2, A3, and A4/A6 roads (Table 3; spatial $C V R^{2}=0.784$ vs. 0.753 , respectively). This model also performed better than the simpler model that used distance to nearest road covariates for A $1-\mathrm{A} 3$ roads (Table 3; spatial CV $R^{2}=0.753$ ). Among only "near-major- road" monitors (those with an $\mathrm{A} 1, \mathrm{~A} 2$, or $\mathrm{A} 3$ road within $300 \mathrm{~m}$, which represented about $47 \%$ of all monitors), these differences were more evident (CV $R^{2}$ of annual averages of 0.762 for ADMS-Roads output summed across A1-A3 roads vs. 0.689 for ADMS-Roads output summed across A1, A2, $\mathrm{A} 3$, and $\mathrm{A} 4 / \mathrm{A} 6$ vs. 0.663 for distance to road covariates).

Results also showed that the spatio-temporal model that included "best-estimate" ADMS-Roads output performed only slightly better than one with "worst-case downwind" ADMS-Roads output when comparing long-term averages (spatial CV $R^{2}=0.784$ vs. 0.775 , respectively). In contrast, on the 24-h average level, the model with "worst-case downwind" ADMS-Roads output performed well and even slightly better than the "best-estimate" ADMS-Roads output (24-h average CV $R^{2}=0.539$ for "worst-case downwind" vs. 0. 532 for "best-estimate"). Despite the influence of daily prevailing wind direction on ADMS-Roads output, these models were quite comparable with respect to predictive accuracy of $\mathrm{PM}_{2.5} \mathrm{EC}$ levels, suggesting that our 24-h prevailing wind direction data from MERRA is only crudely capturing the influence of wind direction; modeling hourly wind direction may provide improvement but is currently impractical at the national scale.

Based on the results above, the final prediction model used "best-estimate" ADMS-Roads output from only road classes A1-A3. However, the model with "worst-case downwind" ADMS-Roads output would provide an acceptable alternative to the "best-estimate" model, especially for analyses focused on shorter averaging time periods. Also, we note that excluding A4 roads results in a large gain in computational efficiency.

Though predictive accuracy was moderate for $\mathrm{PM}_{2.5} \mathrm{EC}$ at the 24-h average level (Table $3 ; 24$-h average CV $R^{2}=0.532$ ), it improved substantially for longer averaging times $\left(\mathrm{CV} R^{2}=\right.$ $0.613,0.679,0.707,0.795$, and 0.784 for weekly, two-week, and monthly, annual-average, and spatial averages, respectively. Predictive accuracy was generally consistent across US Census Divisions (Supplemental Material Table S1). It was also reasonably consistent across tertiles of urban land use, across the four seasons, and across monitoring networks.

Table 3 Cross-validation statistics for the spatio-temporal prediction model (top row) and two alternate models (lower two rows) of 24-h average $\mathrm{PM}_{2.5}$ EC levels in the conterminous US from 1999 to 2011

\begin{tabular}{|c|c|c|c|c|c|c|c|c|c|c|}
\hline \multirow{2}{*}{$\begin{array}{l}\text { Spatio-temporal model } \\
\text { covariates }^{\mathrm{a}}\end{array}$} & \multicolumn{8}{|c|}{ 24-h average values } & \multirow{2}{*}{$\begin{array}{l}\mathrm{CV} R^{2} \text { of } \\
\text { annual } \\
\text { averages }^{\mathrm{f}}\end{array}$} & \multirow{2}{*}{$\begin{array}{l}\text { Spatial } \\
\text { CV } R^{2 \dagger}\end{array}$} \\
\hline & $\mathrm{n}$ & $\begin{array}{l}\text { Model } \\
R^{2 \mathrm{~B}}\end{array}$ & $\underset{\mathrm{C}}{\mathrm{CV}} R^{2}$ & Intercept $^{\mathrm{d}}$ & Slope $^{\mathrm{d}}$ & $\begin{array}{l}\mathrm{NMBF} \\
(\%)^{\mathrm{E}}\end{array}$ & $\mathrm{CVMAE}^{\mathrm{e}}$ & $\begin{array}{l}\text { NMEF } \\
(\%)^{\mathrm{E}}\end{array}$ & & \\
\hline ADMS-Roads output (A1-A3) & 201,425 & 0.679 & 0.532 & 1.4 & 0.74 & -4.8 & 112 & 47.1 & 0.795 & 0.784 \\
\hline $\begin{array}{l}\text { ADMS-Roads output } \\
\text { (A1-A4 and A6) }\end{array}$ & 201,425 & 0.682 & 0.495 & 1.3 & 0.75 & -3.7 & 115 & 47.9 & 0.747 & 0.753 \\
\hline $\begin{array}{l}\text { No ADMS-Roads output } \\
\text { but with distance to road } \\
\text { (A1-A3) terms }\end{array}$ & 201,425 & 0.683 & 0.472 & 1.3 & 0.76 & -4.0 & 117 & 48.7 & 0.723 & 0.753 \\
\hline
\end{tabular}


Fig. 2 Plot of the smooth function of ADMS-Roads output (summed across road classes A1A3) from the spatio-temporal PM2.5 EC model levels. Data on both axes have been transformed from the natural $\log$ to the native scale. The $x$-axis shows the distribution of ADMS-Roads output (summed across road classes A1-A3), at the set of monitors used for model fitting, in red

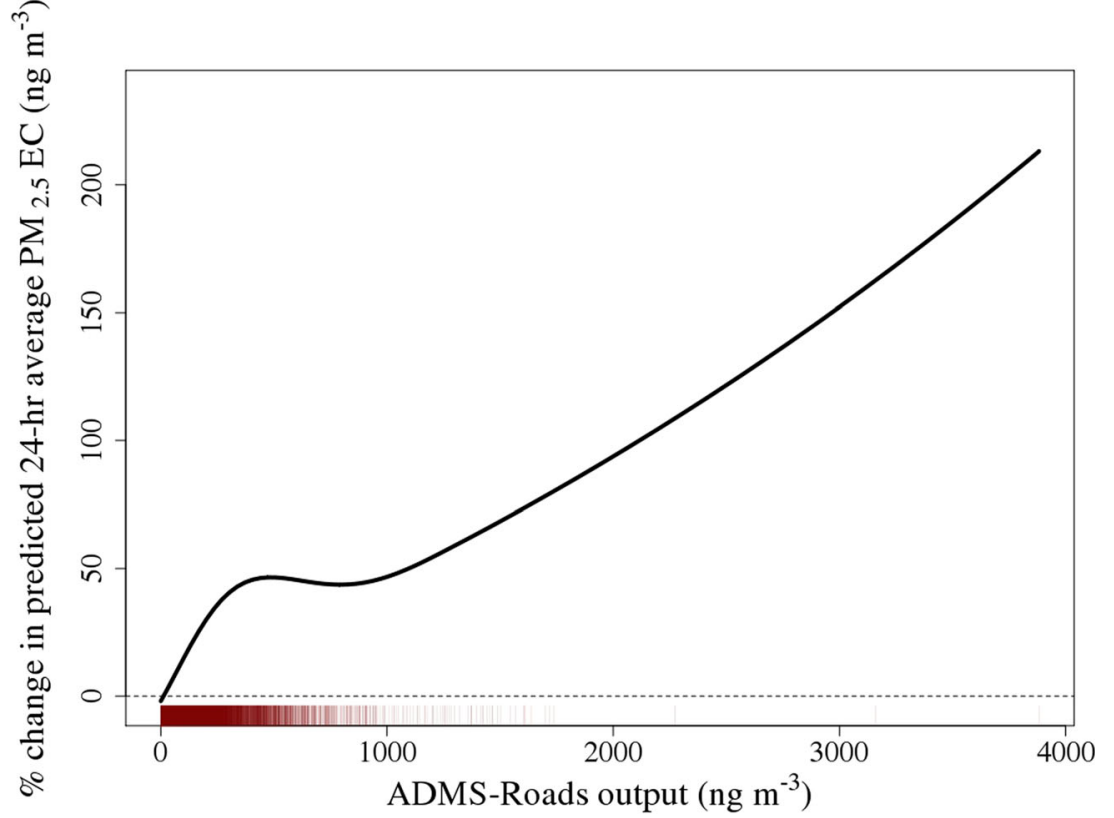

Across monitoring objectives, predictive accuracy was slightly lower at "source-related" sites (categories defined by the US EPA; "source-related" refers to a monitor located nearby to a large point source; $\mathrm{CV} R^{2}$ of annual averages $=0.398$ ). $95 \%$ prediction interval coverage was 0.969 , as compared to a nominal value of 0.95 , indicating that model standard errors though reasonably well scaled, may have been slightly underestimated.

\section{Smooth function of ADMS-Roads output in the spatio-temporal $\mathrm{PM}_{2.5} \mathrm{EC}$ model}

In Fig. 2, the smooth function for ADMS-Roads output summed across $\mathrm{A} 1-\mathrm{A} 3$ roads (shown on the $x$-axis) increases monotonically and nearly linearly from zero to moderate levels around $500 \mathrm{ng} \mathrm{m}^{-3}$, and then begins to flatten. Once the ADMS-Roads output exceeds $1000 \mathrm{ng} \mathrm{m}^{-3}, \mathrm{PM}_{2.5} \mathrm{EC}$ levels again rise, but with a shallower slope.

\section{Smooth functions of other covariates in the spatio-temporal $\mathrm{PM}_{2.5} \mathrm{EC}$ model}

$\mathrm{PM}_{2.5}$ EC levels increased linearly with county-level population density $\left(1.0^{\circ}\right.$ of freedom (df)). For urban land use, $\mathrm{PM}_{2.5}$ EC levels increased monotonically but not linearly (4.0 df), increasing steadily from 0 to about $40 \%$ urban land use, less steeply from 40 to about $80 \%$, and more steeply from about 80 to $100 \%$. For elevation, $\mathrm{PM}_{2.5}$ EC levels decreased nearly linearly from 0 to about $2000 \mathrm{~m}$, and less steeply beyond. $\mathrm{PM}_{2.5}$ EC levels decreased nearly linearly with increasing wind speed, increased in an S-shaped pattern with increasing air temperature, and decreased non-linearly with increasing total rainfall. Plots of each of these smooth functions are shown in the Supplemental Material Fig. S5. Also, details regarding the df used by the spatial terms in the spatiotemporal $\mathrm{PM}_{2.5} \mathrm{EC}$ model can be found in the Supplemental Material.

\section{Spatial patterns in spatio-temporal $\mathrm{PM}_{2.5} \mathrm{EC}$ model-predicted levels}

Figure 3 shows predicted 24-h average $\mathrm{PM}_{2.5}$ EC levels for 2 days in 2008 and averaged across that year. Predicted $\mathrm{PM}_{2.5}$ EC levels are clearly increased near roadways in each plot.

Figure 4 shows predicted 24-h average $\mathrm{PM}_{2.5}$ EC levels on a 6-km grid across the conterminous US for August 4 and 10, 2008, and averaged across 2008. Additional details regarding these figures and the statistical assumptions of our spatiotemporal $\mathrm{PM}_{2.5}$ EC model can be found in the Supplemental Material.

\section{Discussion}

Comparing the two methods of spatial averaging traffic counts, we found that spatial smoothing performed better than the kernel density approach in an external validation using automated traffic recorder data. This is likely due to the different assumptions regarding sparsity of data in space and the manner in which each are affected by extreme values.

For the spatio-temporal $\mathrm{PM}_{2.5}$ EC model, the model $R^{2}$ of 0.679 indicates the model was able to explain much of the variability in measured levels. Local influences that may not be fully described by the spatio-temporal model (i.e., those not 

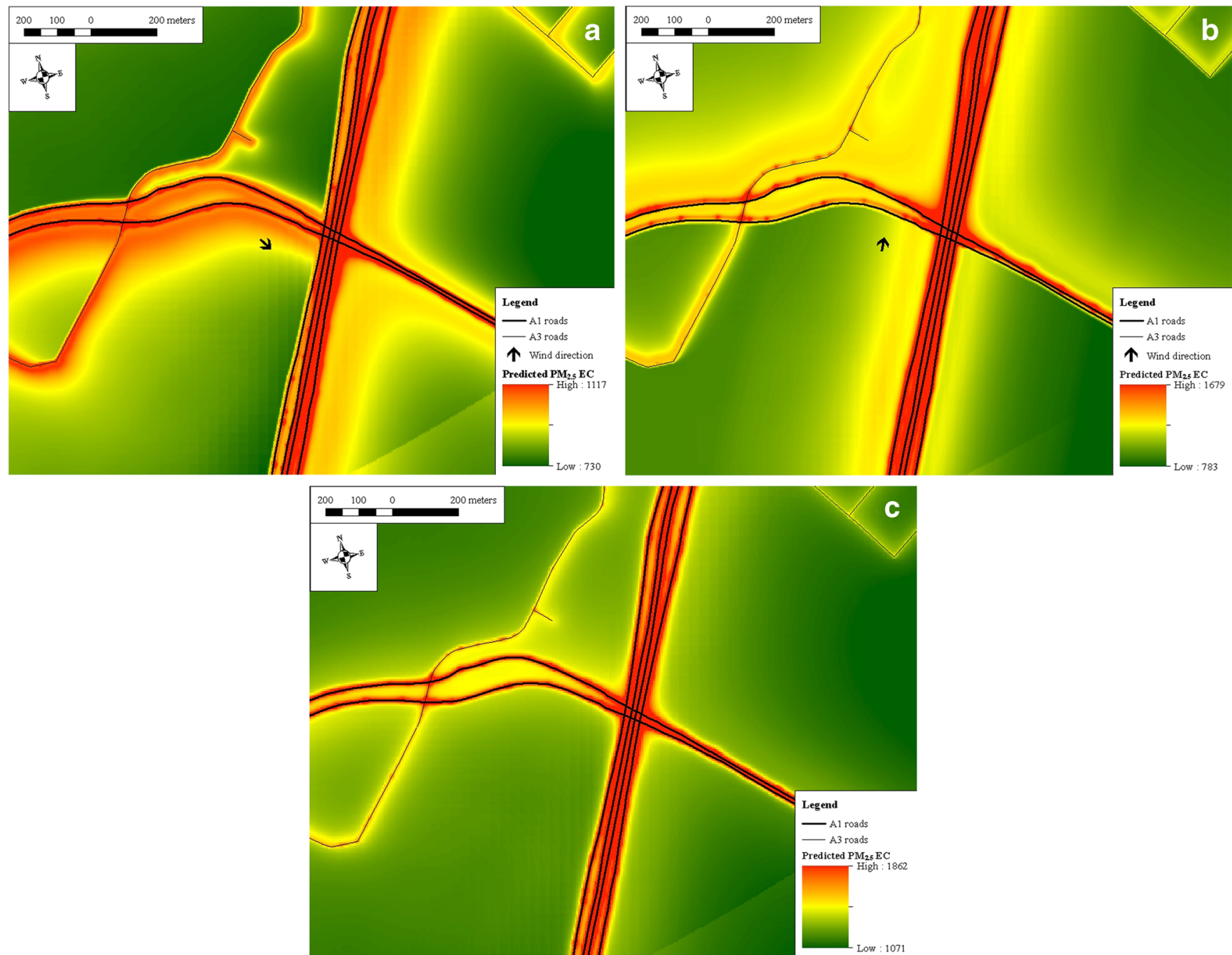

Fig. 3 a Predicted 24-h average $\mathrm{PM}_{2.5}$ EC levels $\left(\mathrm{ng} \mathrm{m}^{-3}\right.$ ), in the same domain as Fig. 1, for August 4, 2008. b Same as A but showing 24-h average levels for August 10, 2008. c Same as A but showing annual-

described by model covariates for traffic-related PM levels, urbanization, elevation, and local meteorology) include local wildland fires, residential wood burning, and industrial sources, all sources of EC. The spatio-temporal $\mathrm{PM}_{2.5} \mathrm{EC}$ model does well in representing spatial trends, and especially so for averaging times longer than 24-h (CV R ${ }^{2}$ for monthly and annual averages $=0.707$ and 0.795 , respectively; spatial CV $\left.R^{2}=0.784\right)$.

The smooth function for ADMS-Roads output (summed across road classes A1-A3) showed a non-linear but monotonically increasing relationship between that covariate and 24-h average $\mathrm{PM}_{2.5}$ EC levels, highlighting the need to use penalized spline smoothing. By including $\mathrm{PM}_{2.5}$ EC monitoring data from all sites in the conterminous US in the same spatio-temporal model, we capture the largest possible range in the ADMS-Roads output covariate.

The similarity in $\mathrm{CV}$ results from the spatio-temporal models with alternative representations of traffic, including average levels for 2008. 5th to 95th percentiles are shown for each. The prevailing wind direction from smoothed MERRA data is shown with black arrows in $\mathbf{a}$ and $\mathbf{b}$

those with distance to road terms instead of ADMS-Roads model output and even among only "near-major-road" monitors, suggests that micro-scale spatial gradients are a relatively small proportion of $\mathrm{PM}_{2.5} \mathrm{EC}$ mass (albeit an arguably important one for health effects analyses). Also, spatial error induced by smoothing sparse traffic count data or imprecision in other ADMS-Roads model inputs may contribute to similarity among CV $R^{2}$ values. Specifically, including the effect of wind direction from the $10-\mathrm{m}$ road source points to the receptor locations improved prediction accuracy as assessed by the spatial CV $R^{2}$ only slightly as compared to the "worst-case downwind" ADMS-Roads output, suggesting that MERRA 24-h prevailing wind direction data (one value per day) are of only limited use in describing primary traffic-related PM levels. Though it would represent a substantial increase in computational demand, hourly wind data, which would reflect changes in wind direction throughout the day, would likely be more realistic and may further increase predictive accuracy. 

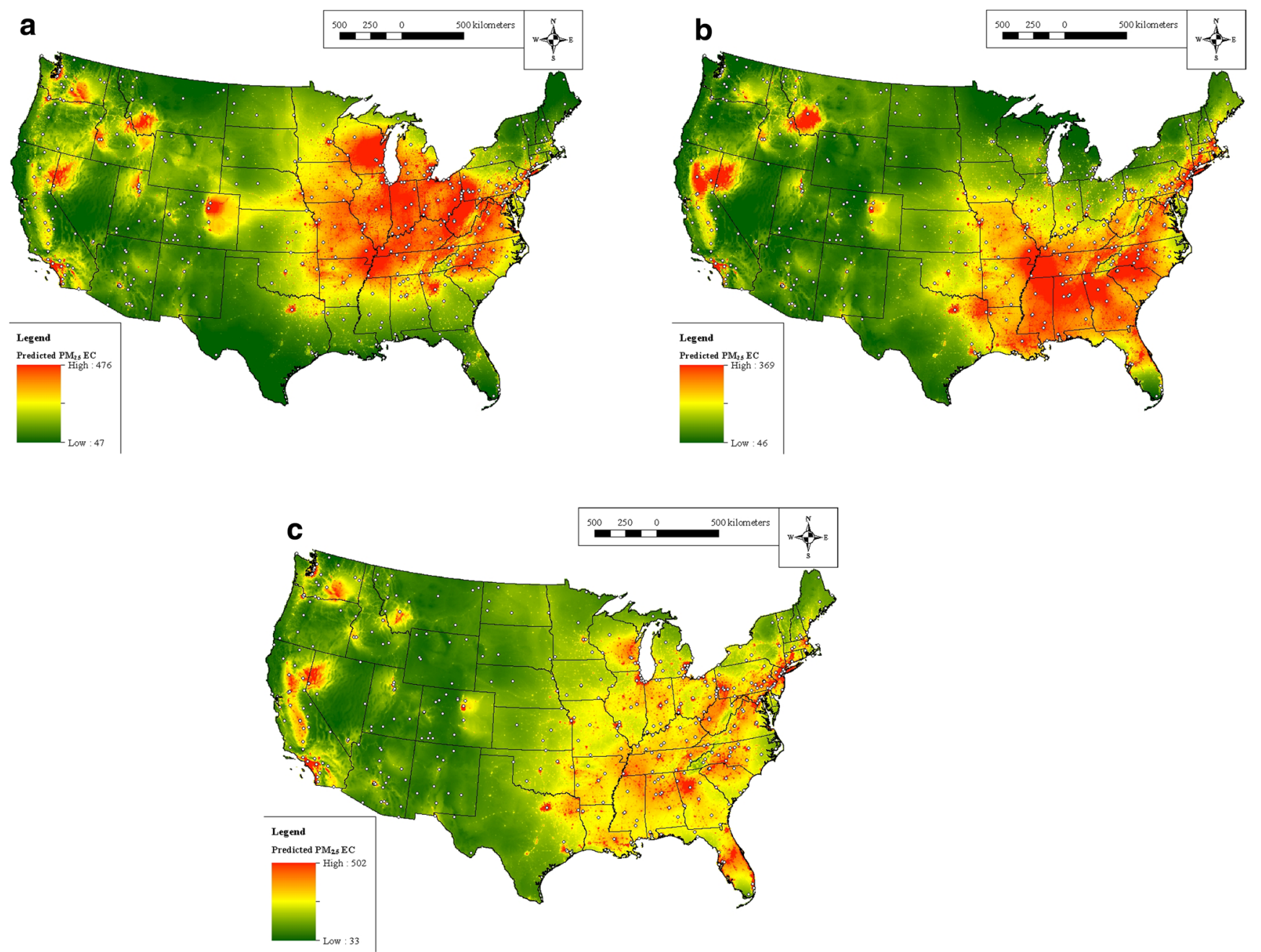

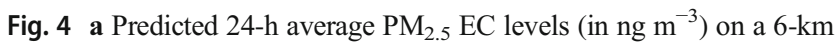
grid in the conterminous US (219,948 cell values each day) for August 4, 2008. b Same as a but showing 24-h average levels for August 10, 2008.

c Same as a but showing annual-average levels for 2008. White points are $\mathrm{PM}_{2.5}$ EC monitors. 5th to 95th percentiles are shown for each

In comparison to previous studies, our methodology is similar to that used in the London Air Pollution Toolkit (Kelly et al. 2011) and in Wilton et al. (2010). However, our methodology is novel in (1) its scope of application, in that it is the first, to our knowledge, to apply a line-source Gaussian plume model to estimate traffic-related PM levels in a consistent manner across the conterminous US, and (2) its use of spatially smoothed road-class-specific traffic counts. In comparison to previous studies, the spatial distribution of long-term mean predicted $\mathrm{PM}_{2.5}$ EC in Fig. 4 is broadly similar to that presented in Bergen et al. (2013). Also, consistent with results in Wilton et al. (2010), we found that including ADMS-Roads output on smaller, lesser trafficked A4/A6 roads did not improve predictive accuracy of the spatio-temporal $\mathrm{PM}_{2.5} \mathrm{EC}$ model.

One advantage of our spatio-temporal model is it avoids spatial discontinuities in predicted levels, such as those caused by moving-windows in Akita et al. (2012) and the use of regional terms in Yanosky et al. (2014), by including data

from the conterminous US in one spatio-temporal model and by using spatially smooth covariates, with the exception of ADMS-Roads output. Though the ADMS-Roads output does contain spatial discontinuities where the traffic intensity changes categories, these were quite small (one is visible in the bottom right of each panel of Fig. 3; this is an extreme example due to the very high traffic intensity in the area shown). However, we do assume stationarity across the domain. In contrast, the moving-window approach in Akita et al. (2012) does not require this assumption.

Maintaining computational feasibility was a key challenge in the development of our traffic-related PM modeling approach. Even the spatial join to identify the 10-m road source points within $2 \mathrm{~km}$ of each $\mathrm{PM}_{2.5}$ monitoring location was computationally demanding, requiring specialized multiprocessing software code to be implemented. Categorization of the several ADMS-Roads inputs was necessary to make computation possible, and to provide a balance of complexity and computational feasibility. 
Our models will be used to provide estimates of exposure to traffic-related $\mathrm{PM}$ and to $\mathrm{PM}_{2.5}$ EC in epidemiologic analyses. Despite advantages over simpler exposure metrics, our traffic-related PM modeling approach has several limitations. One is that annual-average traffic counts do not explain all of the daily variability in traffic intensity; another is that it relies on spatially averaged traffic counts rather than data on each specific road segment. Finely time-resolved (e.g., daily) traffic counts for each road segment in the road network are not currently available. To some extent, this is addressed by performing spatial smoothing separately for each road class. However, traffic count data are spatially incomplete in that not every segment has a traffic count, so error from spatial interpolation is unavoidable. Other spatial averaging methods are also vulnerable to this problem, such as when imputing the mean traffic count based on county boundaries. We note that though our traffic intensity inputs vary smoothly in space, the resulting ADMS-Roads output is not smooth in space due to our application of kernels to the $10-\mathrm{m}$ road source points; therefore, micro-scale detail, down to the resolution of a few meters, is retained. Another limitation is that the approach does not account for bridges, street canyons, tunnels, or other elevation-related effects or for differences in emission factors between light-duty and heavy-duty vehicles, the latter because traffic counts segregated by light- and heavy-duty vehicles were unavailable. Finally, meteorological data were averaged to the daily level and, as discussed above for wind direction, do not reflect hourly variation in meteorological parameters. Other minor limitations include small discontinuities induced by categorization of the input parameters and use of assumed road widths and vehicle speeds. However, the inputs were finely divided into a large number of categories to minimize spatial discontinuities, and assumed road widths and vehicle speeds are likely most influential within 10-20 m of the road centerline, an area where relatively few residences exist. Finally, despite the simplifying assumptions discussed above, the approach presents significant computational challenges with respect to processing time, memory, and disk space and requires parallel computing in order to be implemented on large numbers of locations.

Our spatio-temporal $\mathrm{PM}_{2.5}$ EC model also has several limitations. One is that the data set does not contain multiple monitors within small areas with monitors near and far from major road, data that could help distinguish micro-scale effects, including that of wind direction, from larger spatial scale regional effects. Also, the model makes several statistical assumptions (discussed in the Supplemental Material), such as stationary and isotropic spatial variation, additive covariate effects, and independent and normally distributed model residuals with mean zero and constant variance. Finally, a limitation of all models of exposure to combustion-produced $\mathrm{PM}_{2.5}$ is the combination of continually evolving engine modifications, after-treatment technologies, and fuel blends. The adoption of diesel particulate filters for post-2007 heavy-duty compression ignition engines used in on-road (highway) trucks and busses and reduced sulfur content in diesel fuel have and will continue to reduce particulate emissions from new vehicles.

This work emphasizes the need for spatially accurate, consistently measured, nationwide, and time-resolved information on traffic intensity for each road segment (preferably distinguishing between light-and heavy-duty vehicles). Also, the siting of additional monitoring sites near existing $\mathrm{PM}_{2.5}$ speciation monitors but in locations nearer to large roadways, including those with "population exposure" and "background" monitoring objectives, would be valuable for future development of predictive models of traffic-related air pollutant levels.

\section{Conclusions}

Our approach provides estimates of primary traffic-related PM levels based on line-source Gaussian plume dispersion model output. The methodology can provide high spatial resolution (interpolated from a 2-m grid) estimates of traffic-related PM (both "best-estimate" values that incorporate wind direction and "worst-case downwind" values) across the conterminous US from 1999 to 2011 which account for (1) spatially varying traffic intensity (specific to each road class) and (2) spatiotemporal covariates describing daily local meteorology. In contrast, distance to road terms, often used to represent nearroad traffic-related air pollution levels, do not account for differences in traffic intensity (or at least do not do so within a given road class) or daily local meteorology. Our results demonstrate that ADMS-Roads output describes near-road primary traffic-related PM levels with greater detail and predictive accuracy as compared to distance to road terms in a spatio-temporal $\mathrm{PM}_{2.5}$ EC model; this model had moderate prediction accuracy at the 24-h average level $\left(\mathrm{CV} R^{2}=\right.$ 0.532 ), but better performance when longer-term averages were evaluated $\left(\mathrm{CV} R^{2}\right.$ of annual averages $=0.795$ and spatial CV $R^{2}=0.784$ ). Caution is warranted when using ADMSRoads output as a separate exposure metric because of the non-linear shape of the smooth function in the spatiotemporal $\mathrm{PM}_{2.5}$ EC model levels (Fig. 2). The spatiotemporal model effectively calibrates the ADMS-Roads output to measured $\mathrm{PM}_{2.5} \mathrm{EC}$ levels; predictions from it represent an improved exposure metric for epidemiologic analyses of $\mathrm{PM}$ as compared to distance to road terms.

Acknowledgements We thank Bin Wang for her contribution to the Python programming of several custom Python scripts.

Authors' contributions JDY led and directed the study, performed the analysis, and was the lead writer. JF contributed to the analysis, reviewed 
the manuscript, and participated in revisions. DL reviewed the manuscript. DR reviewed the manuscript. RVW reviewed the manuscript. WG reviewed the manuscript. RCP led the parent study, contributed meaningful intellectual ideas, supervised JF, and reviewed the manuscript. All authors read the manuscript, provided input, and approved the version as submitted.

Funding This research was supported by National Institutes of Health grant \#1 R01 ES019168.

\section{Compliance with ethical standards}

Ethics approval and consent to participate This study was part of the SEARCH For Air project. Informed consent was obtained from study subjects and approval was obtained from the IRB's of both the University of Maryland and the Penn State College of Medicine.

\section{Consent for publication Not Applicable.}

Conflict of interest The authors declare that they have no competing interests.

Abbreviations ADMS, Atmospheric Dispersion Modeling System; ATR, automated traffic recorders; CV, cross-validation; EC, elemental carbon; IMPROVE, Interagency Monitoring of Protected Visual Environments; GAM, generalized additive model; GAMM, generalized additive mixed model; GIS, geographic information system; $\mathrm{L}_{\mathrm{MO}}$, Monin-Obhukov length; MERRA, Modern Era Reanalysis for Research and Applications; $\mathrm{NO}_{\mathrm{x}}$, nitrogen oxide; $\mathrm{NO}_{2}$, nitrogen dioxide; $\mathrm{PM}$, particulate matter; $\mathrm{PM}_{2.5}, \mathrm{PM}<2.5 \mu \mathrm{m} ; \mathrm{PM}_{10}, \mathrm{PM}<10 \mu \mathrm{m}$; USGS, US Geological Survey; WIM, Weigh In Motion

Open Access This article is distributed under the terms of the Creative Commons Attribution 4.0 International License (http:// creativecommons.org/licenses/by/4.0/), which permits unrestricted use, distribution, and reproduction in any medium, provided you give appropriate credit to the original author(s) and the source, provide a link to the Creative Commons license, and indicate if changes were made.

\section{References}

Akita Y, Chen J-C, Serre ML (2012) Moving-window BME: estimation of $\mathrm{PM}_{2.5}$ annual averages. J Exp Sci Env Epi 22(5):496-501

Anderson JO, Thundiyil JG, Stolbach A (2012) Clearing the air: a review of the effects of particulate matter air pollution on human health. $\mathrm{J}$ Med Toxicol 8:166-175

Arain MA, Blair R, Finkelstein N, Brook JR, Sahsuvaroglu T, Beckerman B, Zhang L, Jerrett M (2007) The use of wind fields in a land use regression model to predict air pollution concentrations for health exposure studies. Atmos Environ 41(16):3453-3464

Beelen R, Raaschou-Nielsen O, Stafoggia M, Andersen ZJ, Weinmayr G, Hoffmann B, Wolf K, Samoli E, Fischer P, Nieuwenhuijsen M, Vineis P, Xun WW, Katsouyanni K, Dimakopoulou K, Oudin A, Forsberg B, Modig L, Havulinna AS, Lanki T, Turunen A, Oftedal B, Nystad W, Nafstad P, de Faire U, Pedersen NL, Östenson CG, Fratiglioni L, Penell J, Korek M, Pershagen G, Eriksen KT, Overvad K, Ellermann T, Eeftens M, Peeters PH, Meliefste K, Wang M, Bueno-de-Mesquita B, Sugiri D, Krämer U, Heinrich J, de Hoogh K, Key T, Peters A, Hampel R, Concin H, Nagel G, Ineichen A, Schaffner E, Probst-Hensch N, Künzli N, Schindler C, Schikowski T, Adam M, Phuleria H, Vilier A, Clavel-Chapelon F, Declercq C,
Grioni S, Krogh V, Tsai MY, Ricceri F, Sacerdote C, Galassi C, Migliore E, Ranzi A, Cesaroni G, Badaloni C, Forastiere F, Tamayo I, Amiano P, Dorronsoro M, Katsoulis M, Trichopoulou A, Brunekreef B, Hoek G (2014) Effects of long-term exposure to air pollution on natural-cause mortality: an analysis of 22 European cohorts within the multicentre ESCAPE project. Lancet 383(9919): 785-795

Benson PE (1992) A review of the development and application of the CALINE3 and CALINE4 models. Atmos Environ B Urban Atmos 26(3):379-390

Bergen S, Sheppard L, Sampson PD, Kim S, Richards M, Vedal S et al (2013) A national prediction model for $\mathrm{PM}_{2.5}$ component exposures and measurement error-corrected health effect inference. Environ Health Persp 121(9):1017-1025

Brochu P, Kioumourtzoglou MA, Coull BA, Hopke PK, Suh HH (2011) Development of a new method to estimate the regional and local contributions to black carbon. Atmos Env 45(40):7681-7687

Brugge D, Lane K, Padró-Martínez LT, Stewart A, Hoesterey K, Weiss D, Wang DD, Levy JI, Patton AP, Zamore W, Mwamburi M (2013) Highway proximity associated with cardiovascular disease risk: the influence of individual-level confounders and exposure misclassification. Environ Health 12(1):84

R Development Core Team (2009) R: a language and environment for statistical computing. R Foundation for Statistical Computing, Vienna, Austria. ISBN 3-900051-07-0 Available at: http://www.Rproject.org

Draper D, Krnjacic M (2006) Bayesian model specification. In: Technical report, Dept. Univ. California Santa Cruz, Applied Mathematics and Statistics

Eckel SP, Berhane K, Salam MT, Rappaport EB, Linn WS, Bastain TM, Zhang Y, Lurmann F, Avol EL, Gilliland FD (2011) Residential traffic-related pollution exposures and exhaled nitric oxide in the Children's Health Study. Environ Health Persp 119(10):1472-1477

Gehring U, Heinrich J, Kramer U, Grote V, Hochadel M, Sugiri D et al (2006) Long-term exposure to ambient air pollution and cardiopulmonary mortality in women. Epidemiology 17(5):545-551

Golan R, Ladva C, Greenwald R, Krall JR, Raysoni AU, Kewada P, Winquist A, Flanders WD, Liang D, Sarnat JA (2018) Acute pulmonary and inflammatory response in young adults following a scripted car commute. Air Qual Atmos \& Health 11:123-136

Gryparis A, Coull BA, Schwartz J, Suh HH (2007) Semiparametric latent variable regression models for spatiotemporal modelling of mobile source particles in the greater Boston area. Journ Royal Stat Soc Ser C Appl Stat 56:183-209

Hart JE, Liao X, Hong B, Puett RC, Yanosky JD, Suh H, Kioumourtzoglou MA, Spiegelman D, Laden F (2015) The association of long-term exposure to $\mathrm{PM}_{2.5}$ on all-cause mortality in the Nurses' Health Study and the impact of measurement-error correction. Environ Health 14(1):38

Heinrich J, Thiering E, Rzehak P, Kramer U, Hochadel M, Rauchfuss $\mathrm{KM}$ et al (2013) Long-term exposure to $\mathrm{NO}_{2}$ and $\mathrm{PM}_{10}$ and all-cause and cause-specific mortality in a prospective cohort of women. Occup Environ Med 70(3):179-186

Hoffmann B, Moebus S, Mohlenkamp S, Stang A, Lehmann N, Dragano N, Schmermund A, Memmesheimer M, Mann K, Erbel R, Jockel $\mathrm{KH}$, for the Heinz Nixdorf Recall Study Investigative Group (2007) Residential exposure to traffic is associated with coronary atherosclerosis. Circulation 116(5):489-496

Jerrett M, Arain A, Kanaroglou P, Beckerman B, Potoglou D, Sahsuvaroglu T, Morrison J, Giovis C (2005) A review and evaluation of intraurban air pollution exposure models. 2005. Journ Exposure Anal Environ Epi 15(2):185-204

Kelly F, Anderson HR, Armstrong B, Atkinson R, Barratt B, Beevers S et al (2011) The impact of the congestion charging scheme on air quality in London. Part 1. Emissions modeling and analysis of air 
pollution measurements. Research Report / Health Effects Institute 155:5-71

Legendre P. lmodel2: Model II Regression. R package version 1.7-0. 2011. Available at: http://CRAN.R-project.org/package=lmodel2

Maynard D, Coull BA, Gryparis A, Schwartz J (2007) Mortality risk associated with short-term exposure to traffic particles and sulfates. Environ Health Persp 115(5):751-755

Medina-Ramon M, Goldberg R, Melly S, Mittleman MA, Schwartz J (2008) Residential exposure to traffic-related air pollution and survival after heart failure. Environ Health Persp 116(4):481-485

Paciorek CJ, Yanosky JD, Puett RC, Laden F, Suh HH (2009) Practical large-scale spatio-temporal modeling of particulate matter concentrations. Ann Appl Stat 3:370-397

Pelucchi C, Negri E, Gallus S, Boffetta P, Tramacere I, La Vecchia C (2009) Long-term particulate matter exposure and mortality: a review of European epidemiological studies. BMC Public Health 9: 453

Puett RC, Hart JE, Schwartz J, Hu FB, Liese AD, Laden F (2011) Are particulate matter exposures associated with risk of type 2 diabetes? Environmental Health Persp 119(3):384-389

Puett RC, Hart JE, Yanosky JD, Spiegelman D, Wang M, Fisher J et al (2014) Particulate matter air pollution exposure, distance to road, and lung cancer risk in the Nurses' Health Study cohort. Environ Health Persp 122:926-932

Rich DQ, Utell MJ, Croft DP, Thurston SW, Thevenet-Morrison K, Evans KA, Ling FS, Tian Y, Hopke PK (2018) Daily land use regression estimated woodsmoke and traffic pollution concentrations and the triggering of ST-elevation myocardial infarction: a case-crossover study. Air Qual Atmos \& Health 11:239-244

Schikowski T, Sugiri D, Ranft U, Gehring U, Heinrich J, Wichmann HE, Krämer U (2005) Long-term air pollution exposure and living close to busy roads are associated with COPD in women. Respir Res 6: 152

Shah AS, Langrish JP, Nair H, McAllister DA, Hunter AL, Donaldson K et al (2013) Global association of air pollution and heart failure: a systematic review and meta-analysis. Lancet 382(9897):1039-1048
Silverman BW. 1986. Density Estimation for Statistics and Data Analysis. New York: Chapman and Hall:76. Equation 4.5

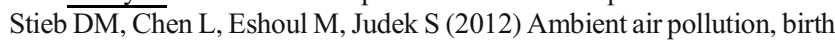
weight and preterm birth: a systematic review and meta-analysis. Environ Res 117:100-111

US Bureau of Transportation Statistics. 2013. National Transportation Atlas web page. Available at: http://www.rita.dot.gov/bts/sites/rita. dot.gov.bts/files/publications/national_transportation_atlas database/2011/index.html [accessed November 16, 2013]

US Census Bureau. 2013. 2010 TIGER/Line Shapefiles web page. Available at: http://www.census.gov/cgi-bin/geo/shapefiles2010/ main [accessed February 9, 2013]

US Geological Survey. 2012. National Land Cover Dataset web page. Available at: http://www.mrlc.gov/nlcd2001.php [accessed June 1, 2012]

US Geological Survey. 2013. National Elevation Dataset web page. Available at: http://nationalmap.gov/elevation.html [accessed May 19, 2013]

Weuve J, Puett RC, Schwartz J, Yanosky JD, Laden F, Grodstein F (2012) Exposure to particulate air pollution and cognitive decline in older women. Arch Intern Med 172(3):219-227

Wilton D, Szpiro A, Gould T, Larson T (2010) Improving spatial concentration estimates for nitrogen oxides using a hybrid meteorological dispersion/land use regression model in Los Angeles, CA and Seattle, WA. Sci Tot Environ 408(5):1120-1130

Wood SN (2006) Generalized additive models: an introduction with R. Chapman \& Hall/CRC, Boca Raton

Yanosky JD, Paciorek CJ, Schwartz J, Laden F, Puett R, Suh HH (2008) Spatio-temporal modeling of chronic $\mathrm{PM}_{10}$ exposure for the Nurses' Health Study. Atmos Environ 42:4047-4062

Yanosky JD, Paciorek CJ, Laden F, Hart J, Puett R, Suh HH (2014) Spatio-temporal modeling of particulate air pollution in the conterminous United States using geographic and meteorological predictors. Environ Health 13(1):63

Zhou Y, Levy JI (2007) Factors influencing the spatial extent of mobile source air pollution impacts: a meta-analysis. BMC Pub Health 7:89 